\title{
Effect of Bismuth Addition on Structure and Mechanical Properties of Tin-9Zinc Soldering Alloy
}

\author{
Muhommad Abdul Wadud1, M. A. Gafur2*, Md. Rakibul Qadir², \\ Mohammad Obaidur Rahman' \\ ${ }^{1}$ Department of Physics, Jahangirnagar University, Savar, Bangladesh \\ ${ }^{2}$ PP\&PDC, BCSIR, Dhaka, Bangladesh \\ Email: ${ }^{*} d r$ magafur@yahoo.com
}

Received 28 August 2015; accepted 13 September 2015; published 16 September 2015

Copyright $@ 2015$ by authors and Scientific Research Publishing Inc.

This work is licensed under the Creative Commons Attribution International License (CC BY). http://creativecommons.org/licenses/by/4.0/

(c) () Open Access

\section{Abstract}

$\mathrm{Sn}-\mathrm{Zn}$ based solder is a possible replacement of $\mathrm{Pb}$ solder because of its better mechanical properties. The alloys need to be studied and explored to get a usable solder alloy having better properties. In this work eutectic Sn-9Zn and three Tin-Zinc-Bismuth ternary alloys were prepared and investigated their microhardness and mechanical properties. Microhardness, tensile strength and elastic modulus increase with Bi addition while ductility decreases with Bi addition.

\section{Keywords}

\section{Lead Free Solder Alloy, Eutectic Alloy, Microhardness}

\section{Introduction}

Soldering alloy is the prime material for electronic packaging. Selecting proper material for soldering is important. Melting temperature, mechanical properties, wetting properties and low cost, etc. are very important issues for selecting a solder material. Tin-Lead solders have been widely used in electronic and optoelectronic packaging due to their low cost and low melting temperature and good soldering properties. But lead is an aggressive threat for human health and the environment due to its toxicity. Many countries banned using lead and lead alloys [1] [2] for their use in packaging. Waste Electronic and Electronic Equipment (WEEE) and Restriction of Hazardous Substances (ROHS) approved banning the use of lead in EU countries from July 2006. The USA, the EU and Japan forbade the use of Lead containing products [3] [4]. Au-Sn is thought as an alternative but its

"Corresponding author.

How to cite this paper: Wadud, M.A., Gafur, M.A., Qadir, Md.R. and Rahman, M.O. (2015) Effect of Bismuth Addition on Structure and Mechanical Properties of Tin-9Zinc Soldering Alloy. Materials Sciences and Applications, 6, 792-798.

http://dx.doi.org/10.4236/msa.2015.69081 
mechanical properties are not sufficient [5]-[7]. SAC solder is also an alternative which has eutectic point at $217^{\circ} \mathrm{C}$ [8] and good wetting properties [9]. The search for a Lead-free solder alloy with equivalent mechanical and thermal properties to Sn-Pb solder is an urgent task. A large number of studies on Lead-free solders were being conducted worldwide to find an appropriate replacement. Nowadays Sn-Ag base alloys containing one or more additional metal are being used as alternating soldering alloy [10]-[13]. Mechanical properties such as microhardness, tensile strength elongation and elastic modulus are very important factors for selecting a solder alloy. Recently Sn-Zn eutectic alloys have received particular attention due to its mechanical properties [14] [15]. Hence $\mathrm{Sn}-\mathrm{Zn}$ based alloys are considered as a good candidate for the replacement of traditional $\mathrm{Pb}$-containing solder alloy [16]-[18]. However, available information in literature about the evolution and properties of Sn-Zn based solder alloys is not enough [19]. Mechanical properties of Sn-Zn alloy can be developed by adding small amount of a third element. Bismuth significantly lowers the melting temperature and increases wettability [20]-[22]. In this study four Sn-Zn-Bi alloys were developed containing 0\%, 1\%, 2\% and 3\% Bismuth and their microhardness and tensile properties were measured. Microhardness testing of the samples is carried out to compare the mechanical properties of the samples. Observing microhardness it is easier to monitor the mechanical properties while the tensile testing result gives inconsistent results with a wide scatter due to the strong dependence on the sample surface quality [23]. We prepared four alloys which contained $0 \%, 1 \%, 2 \%$ and $3 \% \mathrm{Bi}$.

\section{Experimental Work}

Sn-Zn-Bi solder alloys were prepared by using Tin, Zinc and Bi with 99.9\% purity. Four alloys compositions were prepared and studied here. Proper amount of Sn and $\mathrm{Zn}$ were melted in a muffle furnace using a clay-graphite crucible at $450^{\circ} \mathrm{C}$ temperature for 30 minutes. Then Bi was added and the mixture again kept in furnace for 10 minutes and then the liquid alloy poured in a cast iron mold having dimensions $300 \mathrm{~mm} \times 10 \mathrm{~mm} \times 10 \mathrm{~mm}$ and mold thickness was $10 \mathrm{~mm}$. The as cast alloys were sectioned using hacksaw. Then they were polished with emery paper and finally wet polished. Polished samples were then cleaned and etched by ethanol with $5 \% \mathrm{HNO}_{3}$ to observe microstructure. Prepared samples were investigated for optical microscope (NMM 800TRF, MTI Corporation, USA). Scanning micrograph were observed with JOEL JSM-7600F scanning electron microscope. Polishing was also necessary to get smooth and parallel surface for hardness study. Hardness of the samples was measured by HMV-2T, Shimadzu Co., Japan, Vickers Microhardness tester. The applied load was 100 gm for 6 seconds and five readings were taken at room temperature to get average value of micrehardness. Tensile properties of the samples were measured with the Hounsfield 10KS Universal Testing Machine. In this paper alloys are referred as Sn-9Zn, Sn-8Zn-1Bi, Sn-7Zn-2Bi and Sn-6Zn-3Bi according to Table 1. The Pouring temperature of the liquid solder alloys and the preheating temperature of the metal mold are $450^{\circ} \mathrm{C}$ and $220^{\circ} \mathrm{C}$, respectively.

\section{Results and Discussion}

\subsection{Microstructure Study}

The optical and SEM micrograph of the Sn-9Zn alloy are shown in Figure 1(a) and Figure 1(b). Figure 1(a) shows the typical lamella of eutectic microstructure. It has been mentioned that eutectic Sn-9Zn alloy consists of $\beta$-Sn and $\mathrm{Zn}$ rich phases. In the micrograph the bright regions are $\beta$-Sn phases and the dark phases are needlelike Zn-rich phase in the $\beta$-Sn matrix. The solid solubility of $\mathrm{Sn}$ in $\mathrm{Zn}$ is less than $0.05 \mathrm{wt} \%$ and the maximum solid solubility of $\mathrm{Zn}$ in Sn is approximately $2 \mathrm{wt} \%$ [24]. Massalski found that no intermetallic compounds exist and there are the Zn solid solution and Sn solid solution in the binary Zn-Sn system [25]. Figures 2-4 show the optical

Table 1. Composition of the alloy.

\begin{tabular}{cccc}
\hline Alloy & Sn (wt\%) & Zn (wt\%) & Bi (wt\%) \\
\hline Sn-9Zn & 91 & 9 & 0 \\
Sn-8Zn-1Bi & 91 & 8 & 1 \\
Sn-7Zn-2Bi & 91 & 7 & 2 \\
Sn-6Zn-3Bi & 91 & 6 & 3 \\
\hline
\end{tabular}




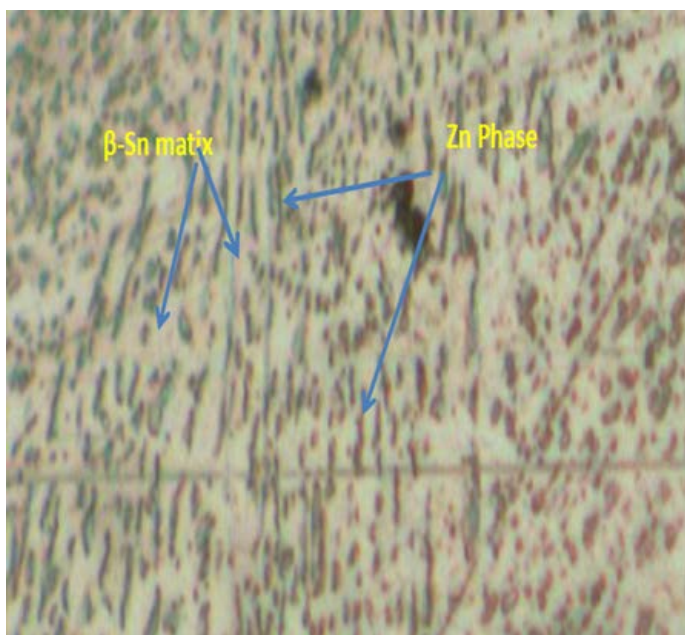

(a)

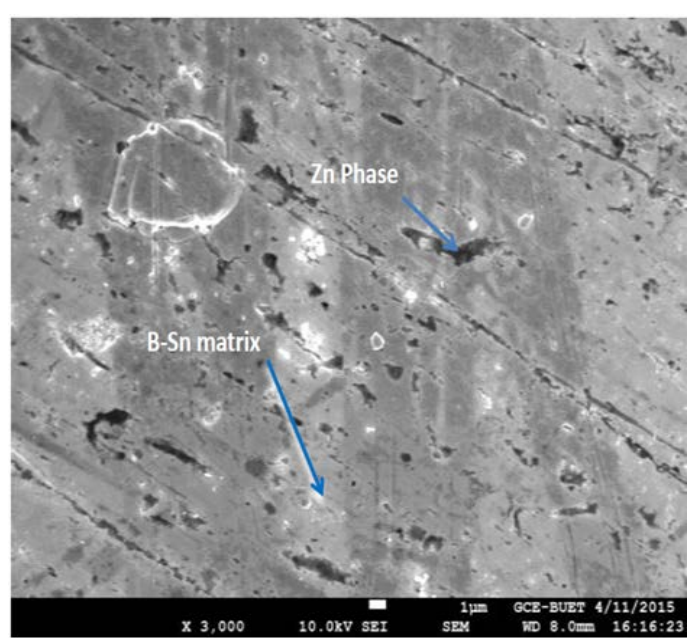

(b)

Figure 1. Optical micrograph (a) and SEM micrograph (b) of Sn-9Zn alloy.

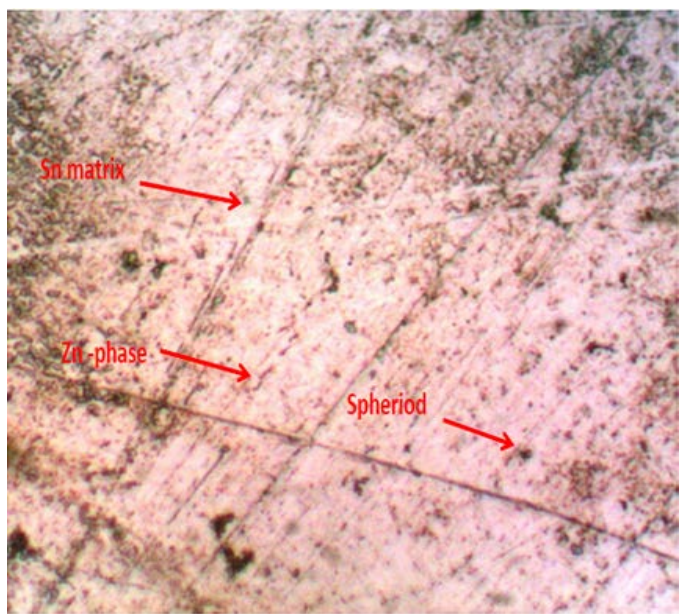

(a)

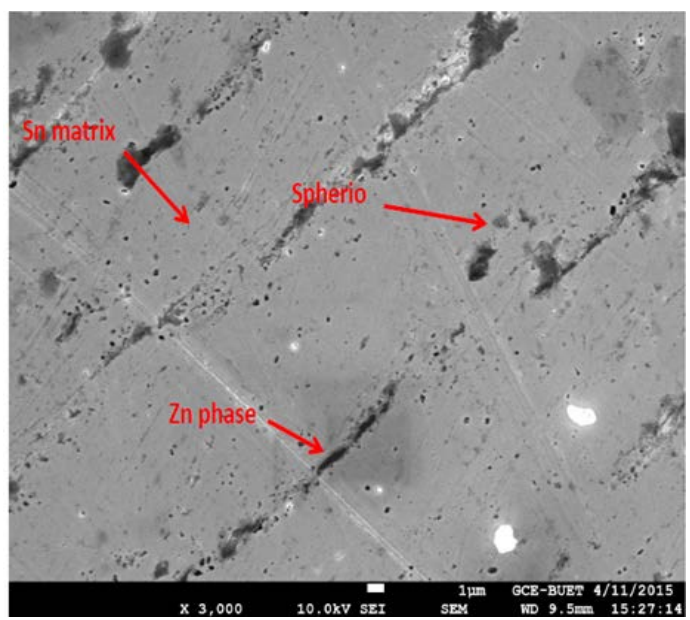

(b)

Figure 2. Optical micrograph (a) and SEM micrograph (b) of Sn-8Zn-1Bi alloy.

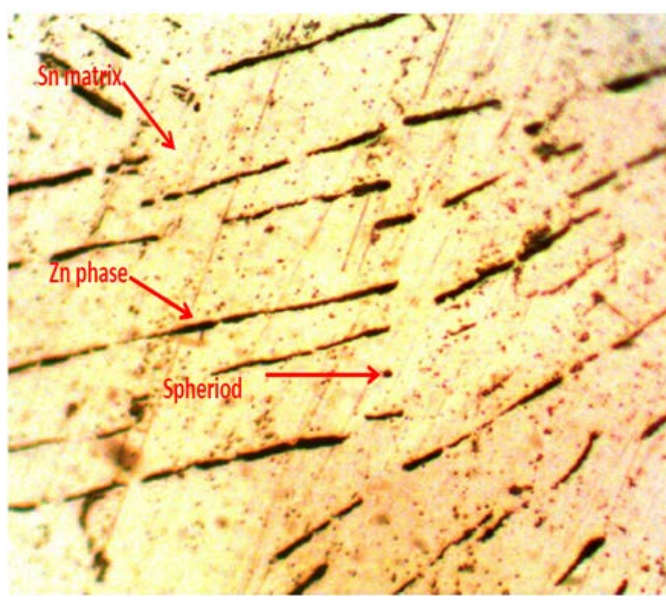

(a)

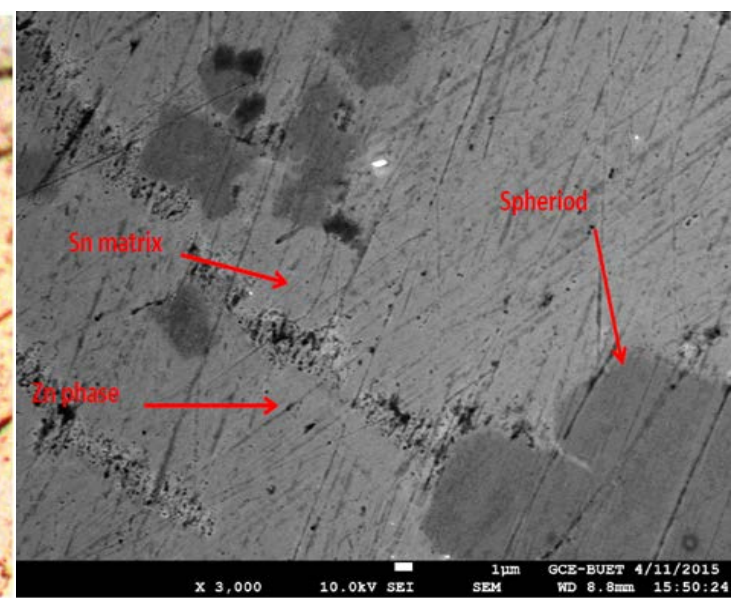

(b)

Figure 3. Optical micrograph (a) and SEM micrograph (b) of Sn-7Zn-2Bi alloy. 


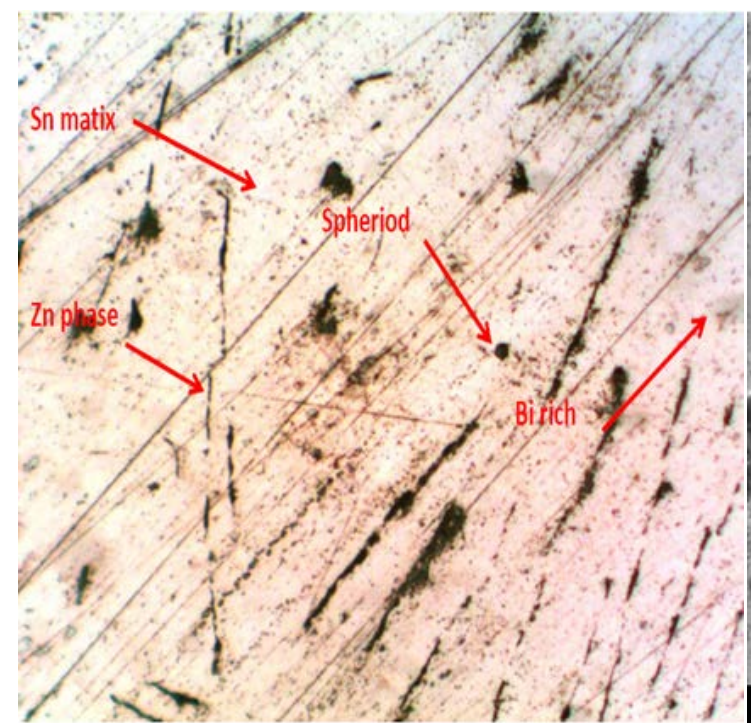

(a)

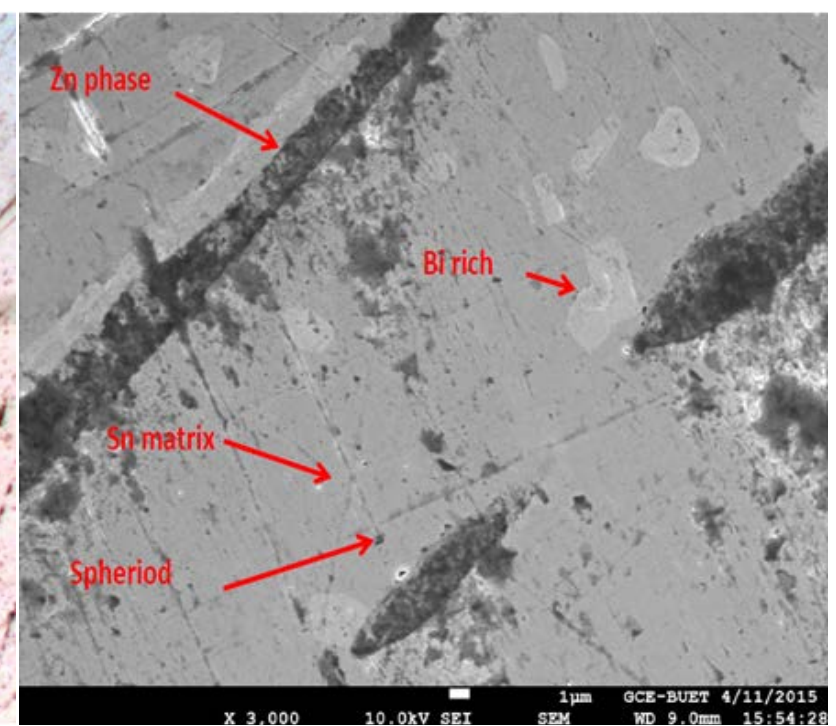

(b)

Figure 4. Optical micrograph (a) and SEM micrograph (b) of Sn-6Zn-3Bi alloy.

micrograph and SEM micrograph of Sn-(9-x)Zn-xBi alloy. Dark needle like Zn phases also observed in the microstructure of Sn- $(9-x) Z n-x B i$ alloy which is uniformly distributed in the Sn matrix like Sn-Zn alloy. Size of the needles becomes larger with the increase of $\mathrm{Bi}$ addition. Some small spheroids are also observed which becomes larger with Bi content. Bi phase was not identified in the alloys with $1 \%$ and $2 \% \mathrm{Bi}$. While it was identified with 3\% Bi. Similar result were obtained by other authors [26] [27] and reasoned that Bi is soluble in $\beta$-Sn and up to 3wt\% Bi can remain in solid solution. This may cause Bi phase not visible in Sn matrix.

\subsection{Microhardness}

Microhardness of Sn-(9-x)Zn-xBi alloy is shown in Figure 5. The figure reveals that microhardness of Sn-9Zn alloy increases with Bi addition. Microhardness continuously increases with the increases of Bi due to solid solution hardening. Mechanical properties such as microhardness depends on microstructure, processing temperature, the composition etc. [28]. The hardness of Sn based solder alloys strongly depends on the alloying element [29]. Bi is soluble in $\beta$-Sn and up to $3 \mathrm{wt} \% \mathrm{Bi}$ can remain in solid solution. The implication of this would be to expect some contribution to hardening from solid solution [26] [27].

\subsection{Tensile Properties}

Figure 6 shows the stress-strain curves of the Sn- $(9-x) \mathrm{Zn}-\mathrm{xBi}$ alloys. It is seen that tensile behavior of Sn- $(9-x) Z n-x B i$ alloys are almost similar. From the figure it is observed that the stress increases to maximum then continues to decrease slowly and eventually suddenly drops to zero. The ultimate tensile strength (UTS), elongation and the elastic modulus of $\mathrm{Sn}-(9-\mathrm{x}) \mathrm{Zn}-\mathrm{xBi}$ alloys are also calculated from the stress-strain curves and the results are shown in Figures 7-9. Addition of Bi increases the UTS and Elastic Modulus of Sn-Zn alloy where as the elongation decreases with $\mathrm{Bi}$ addition due to solid solution hardening. Another author observed similar properties with $\mathrm{Bi}$ [30]. From the microstructure it is observed that $\mathrm{Bi}$ phase is visible in the alloy with $3 \% \mathrm{Bi}$ addition. Hence the increase in UTS and elastic modulus in Sn-6Zn-3Bi can be explain in view of the dispersion strengthening theory [31] which indicates that the strength of a metal or an alloy must be increased with the addition of a second phase particle in the matrix.

\section{Conclusion}

Properties of Sn-Zn alloy change with Bi addition. Bi phase is not visible when the amount of Bi is less than 3\% in the alloy. Microhardness of Sn-Zn alloy increases with Bi addition. Tensile strength and elastic modulus of $\mathrm{Sn}-\mathrm{Zn}$ alloy increase with Bi addition. Elongation of the Sn-Zn alloy decreases with Bi addition. 


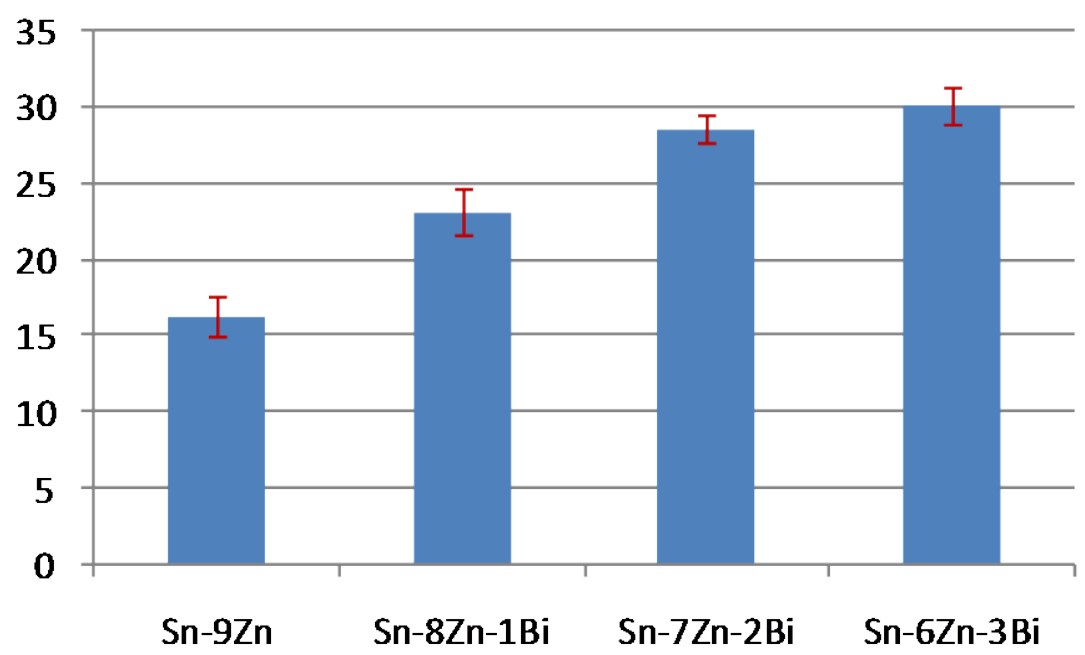

Figure 5. Microhardness of Sn-(9-x)Zn-xBi alloy.

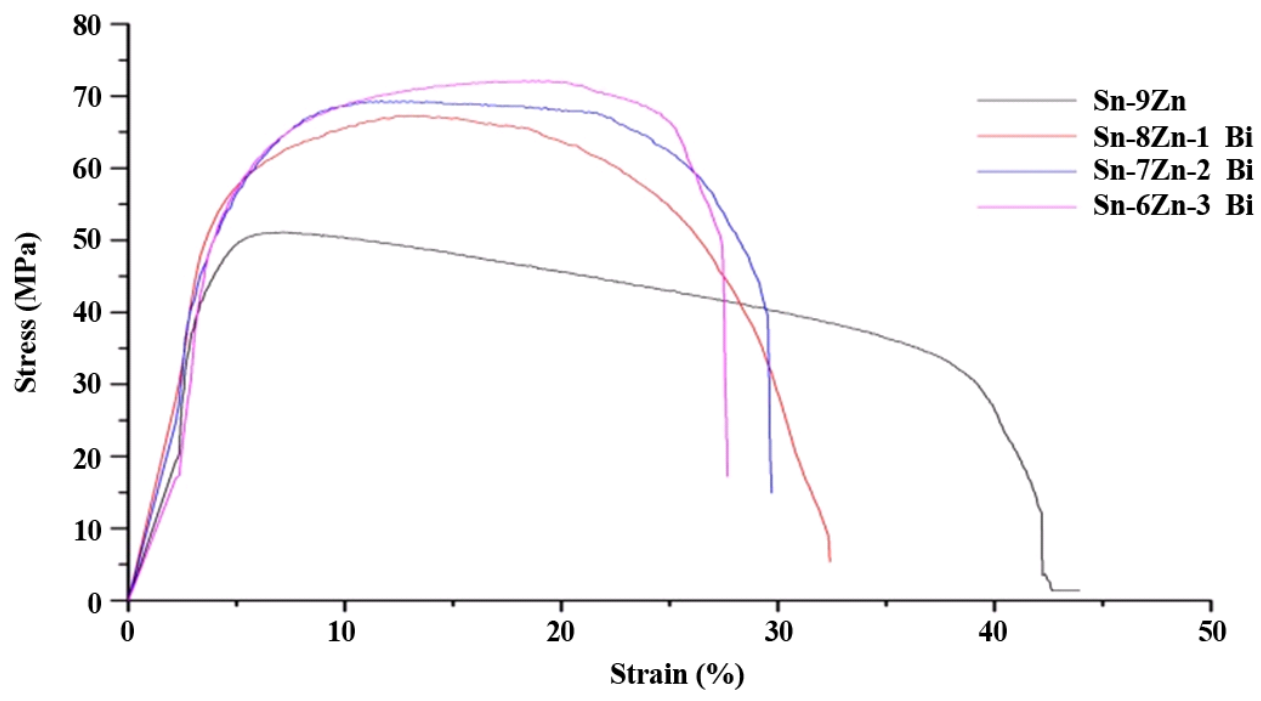

Figure 6. Stress-strain curve of Sn-(9-x)Zn-xBi alloy.

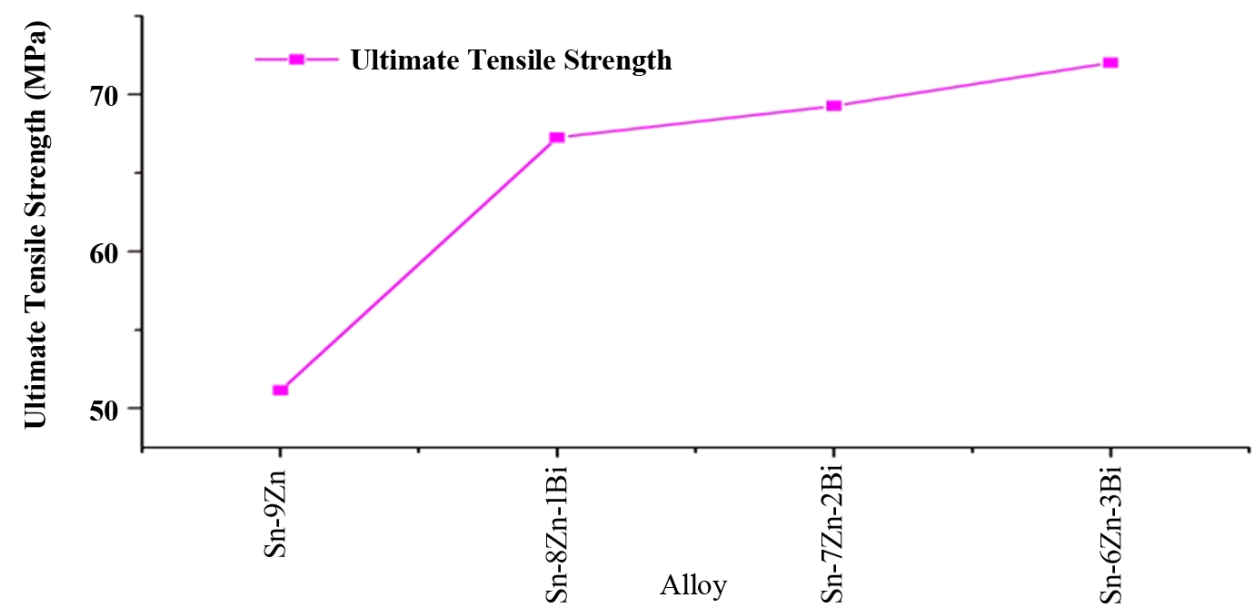

Figure 7. Tensile strength of Sn-(9-x)Zn-xBi alloy. 


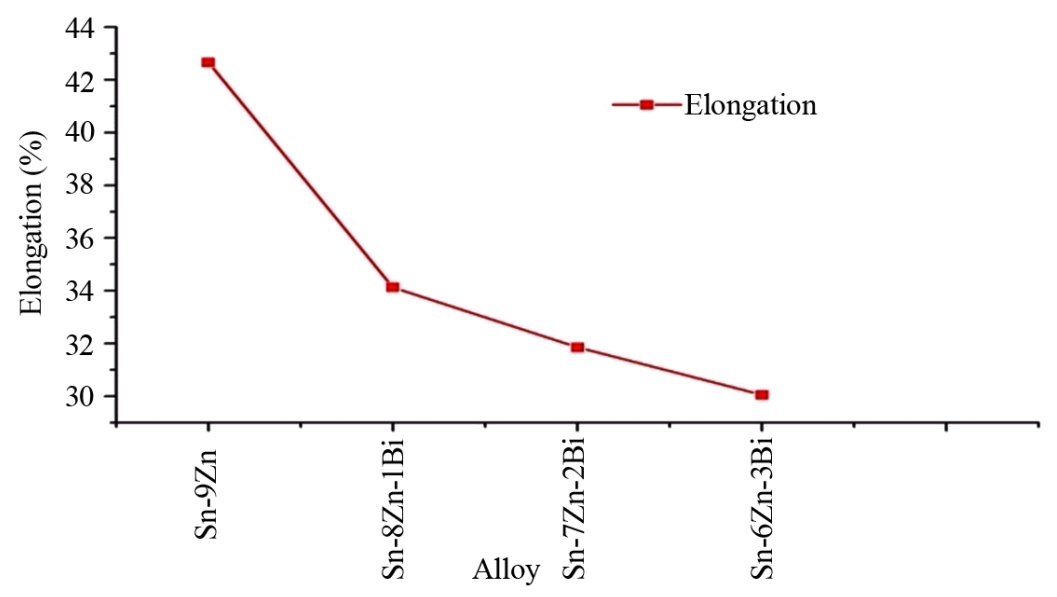

Figure 8. Elongation of Sn-(9-x)Zn-xBi alloy.

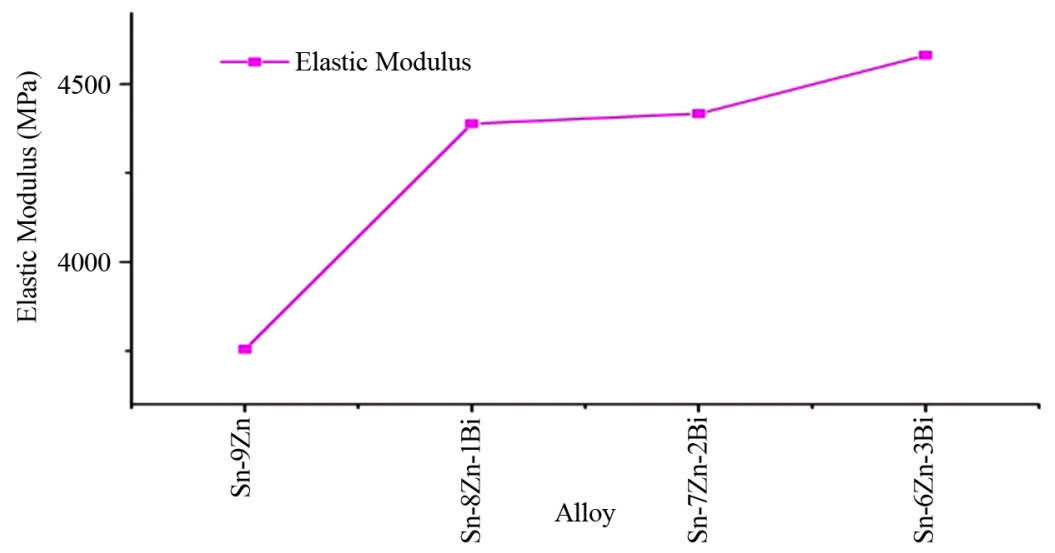

Figure 9. Elastic Modulus of Sn-(9-x)Zn-xBi alloy.

\section{Acknowledgements}

The Authors are grateful to Bangladesh Council of Scientific and Industrial Research for providing them with the research facilities to carry out the work.

\section{References}

[1] McCormack, M., Jin, S. and Chen, H.S. (1994) New Lead-Free, Sn-Zn-In Solder Alloys. Journal of Electronic Materials, 23, 687-690. http://dx.doi.org/10.1007/BF02653357

[2] Suganuma, K. (2001) Advances in Lead-Free Electronics Soldering. Current Opinion in Solid State \& Materials Science, 5, 55-64. http://dx.doi.org/10.1016/S1359-0286(00)00036-X

[3] Matsugi, K., Iwashta, Y., Choi, Y.-B., Sasaki, G. and Fujii, K. (2011) Long Time Stability of Pb-Free Sn-9Zn Elements for Ac-Low Voltage Fuse Performance. Materials Transaction, 52, 753. http://dx.doi.org/10.2320/matertrans.M2010389

[4] US Environmental Protection Agency (1991) Comprehensive Review of Lead in the Environment under TSC, 56FR22096-98.

[5] Debski, A., Gasior, W., Moser, Z. and Major, R. (2010) Enthalpy of Formation of Intermetallic Phases from the Au-Sn System. Journal of Alloys and Compounds, 491, 173-177. http://dx.doi.org/10.1016/j.jallcom.2009.11.003

[6] Chung, H.M., Chen, C.M., Lin, C.P. and Chen, C.J. (2009) Microstructural Evolution of the Au-20 wt.\% Sn Solder on the Cu Substrate during Reflow. Journal of Alloys and Compounds, 485, 219-224. http://dx.doi.org/10.1016/j.jallcom.2009.06.018

[7] Zeng, G., McDonald, S. and Nogita, K. (2012) Development of High-Temperature Solders: Review. Microelectronics Reliability, 52, 1306-1322. http://dx.doi.org/10.1016/j.microrel.2012.02.018 
[8] Matahir, M., Chin, L.T., Tan, K.S. and Olofinjana, A. (2011) Mechanical Strength and Its Variability in Bi-Modified Sn-Ag-Cu Solder Alloy. Journal of Achievements in Material and Manufacturing Engineering, 46, 1.

[9] Cheng, Y.-T., Chan, Y.-T. and Chen, C.-C. (2010) Wettability and Interfacial Reactions between the Molten Sn-3.0 wt\% Ag-0.5 wt\% Cu Solder (SAC) and Ni-Co Alloys. Journal of Alloys and Compounds, 507, 419-424. http://dx.doi.org/10.1016/j.jallcom.2010.08.006

[10] Alam, M.O., Chan, Y.C. and Tu, K.N. (2003) Lead-Free Solders: Materials Reliability for Electronics. Journal of Applied Physics, 94, 4108. http://dx.doi.org/10.1063/1.1602563

[11] Chiu, M.Y., Wang, S.S. and Chuang, T.H. (2002) Intermatallic Compounds Formed during Interfacial Reactions between Liquid Sn-8Zn-3Bi Solders and Ni Substrates. Journal of Electronic Materials, 311, 494-499.

[12] Lee, H.-T., Lin, H.-S., Lee, C.-S. and Chen, P.-W. (2005) Reliability of Sn-Ag-Sb Lead-Free Solder Joints. Materials Science and Engineering: A, 407, 36-44. http://dx.doi.org/10.1016/j.msea.2005.07.049

[13] Abtew, M. and Selvaury, G. (2000) Lead-Free Solders in Microelectronics. Materials Science and Engineering: R, 27, 95-141. http://dx.doi.org/10.1016/S0927-796X(00)00010-3

[14] Cheng, S.-C. and Lin, K.-L. (2005) Microstrucure and Mechanical Properties of Sn-8.55Zn-1Ag-XAl Solder Alloys. Materials Transactions, 46, 42-47.

[15] Azizan, F.M., Purwanto, H. and Mustafa, M.Y. (2012) Effect of Adding Ag on Tensile and Microstructure Properties of Zinc Alloy. IJET-IJENS, 12, 78-84.

[16] Suganumak, K. and Kim, K.S. (2007) Sn-Zn Low Temperature Solder. Journal of Materials Science-Materials in Electronics, 18, 121-127. http://dx.doi.org/10.1007/s10854-006-9018-2

[17] Wang, H., Xue, S.B., Han, Z.J. and Wan, J.X. (2007) Research Status and Prospect of Sn-Zn Based Lead-Free Solders. Welding and Joining, 2, 31-35.

[18] El Daly, A.A. and Hammad, A.E. (2010) Elastic Properties and Thermal Behavior of Sn-Zn Based Lead-Free Solder Alloys. Journal of Alloys and Compounds, 505, 793-800.

[19] Zhao, G.J., Sheng, G.M., Wu, L.L. and Yuan, Z.J. (2012) Interfacial Characteristics and Microstructureal Evolution of Sn-6.5Zn Solder/Cu Substrate Joints during Aging. Transactions of Nonferrous Metals Society of China, 22, 19541960. http://dx.doi.org/10.1016/S1003-6326(11)61413-1

[20] Betrabet, H.S., McGee, S.M. and McKinlay, J.M. (1991) A Nano Structural Design to Produce High Strength Al Alloys with Enhance Electrical Conductivity. Scriptametallurgica et Materialia, 25, 2323-2328. http://dx.doi.org/10.1016/0956-716X(91)90023-T

[21] Russell, A.M. and Lee, K.L. (2005) Stucture-Property Relations in Nonferrous Metals. John Wiley \& Sons, Hoboken. http://dx.doi.org/10.1002/0471708542

[22] Pinizzotto, R.F., Wue, Y., Jacobs, E.G. and Foster, L.A. (1992) Microstructural Development in Composite Solders Caused by Long Time, High Temperature Annealing. Proceedings of the Technical Program-Nepcon West Conference, 3, 1284-1298.

[23] Cadirli, E., Boyuk, U., Kaya, H. and Marash, N. (2011) Determination of Mechanical, Electrical and Thermal Properties of the Sn-Bi-Zn Ternary Alloy. Journal of Non-Crystalline Solids, 375, 2876-2881.

[24] Yoon, J.W. and Jung, S.B. (2007) Solder Joint Reliability Evaluation of Sn-Zn/Au/Ni/Cu Ballgrid-Array Package during Aging. Materials Science and Engineering: A, 452-453, 46-54. http://dx.doi.org/10.1016/j.msea.2006.10.163

[25] Massalski, T.B. (1990) Binary Alloy Phase Diagrams. ASM International, Materials Park.

[26] Matahir, M., Chin, L.T., Tan, K.S. and Olofinjana, A.O. (2011) Mechanical Strength and It's Variability in Bi-Modified Sn-Ag-Cu Solder Alloy. Journal of Achievements in Materials and Manufacturing Engineering, 46, 50-56.

[27] Gouda, E.S. and Aziz, H.A. (2012) Effect of Bi-Additions on Structure and Properties of Sn-9Zn-1Ag Lead-Free Solder Alloys. Journal of Materials Science and Engineering B, 2, 6381-6388.

[28] Frear, D., Morgan, H., Burchett, S. and Lau, J. (1994) The Microstructure of the Solder Alloy Znterconects. Van Nostrand Reinhold, New York.

[29] Islam, S.M.K.N., Sharif, A. and Alam, T. (2012) Intefacial Microstructure, Microhardness and Tensile Properties of Al Microparticle Doped Sn-9Zn Eutectic Pb-Free Solder Alloy for Microelectronics Applications. Journal of Telecommunication, Electronic and Computer Engineering, 4.

[30] Zhou, J., Sun, Y.S. and Xue, F. (2005) Properties of Low Melting Point Sn-Zn-Bi Solders. Journal of Alloys and Compounds, 397, 260-264.

[31] Dieter, G.E. (1986) Mechanical Metallurgy. McGraw-Hill Book Co., New York. 